\title{
Business model innovation of Qingdao Youzhu Decoration Company
}

\author{
Liu Haibing ${ }^{12, a,}$ Kan Yuyue ${ }^{1, b}$ \\ ${ }^{1}$ School of Economic and Management, Lanzhou jiaotong University, Lanzhou \\ ${ }^{2}$ School of Management, zhejiang University, Hangzhou
}

\begin{abstract}
There are many problems in home decoration industry, such as imperfect industry system, lack of integrity of enterprises, low quality of construction personnel, etc. However, Qingdao Youzhu Home Decoration Co., Ltd. has achieved rapid growth with the innovation of business model. Therefore, based on Qingdao Youzhu Home Decoration Co., Ltd., this paper attempts to analyze the company's business model innovation. The conclusion shows that the company's business model canvas includes nine modules of important partners, value proposition, key business, core resources, customer segmentation, customer relationships, Channel access, revenue sources and cost structure, and each module plays an important role.
\end{abstract}

\section{INTRODUCTION}

With the development of China's home decoration industry, it has changed from the traditional mode, wholehouse decoration mode, package mode to the current integrated mode ${ }^{[1]}$. However, under the development of the integrated model, problems such as inadequate home decoration industry systems, insufficient integrity of home decoration companies, and low quality of construction personnel have gradually emerged ${ }^{[2]}$. Under such circumstances, there are more and more calls for a good home decoration market environment by innovating business models. The essence of enterprise competition lies in the business model rather than the product or the price. The mature business model means that the enterprise has built a value ecosystem. The business model has shifted from focusing on its own technology and products to integrating internal and external factors and resources, building a value creation network and a core competitive operation system in collaboration with markets, customers and partners. In the end, respond to customers' demands in the best way, create customer value, and enterprises achieve a win-win situation of the whole value network and ecosystem ${ }^{[3]}$. Therefore, based on Qingdao Youzhu Home Decoration Company, this paper attempts to analyze the reason for its success, namely, the innovation of business model.

\section{Case introduction}

Youzhu Home Decoration Co., Ltd. is a dazzling star enterprise among many incubators. The start-up company, located in Qingdao Jiaozhou Smart Home Industrial Park, was established in July 2014. Under the leadership of founders Yang Tienan and $\mathrm{Li} \mathrm{Pi}$, it has locked into a standardized home decoration market, committed to improving the quality of decoration products and improving the emotional satisfaction solutions of users, and has built a home-centered emotional and material alliance enterprise.

\section{Case analysis}

The rapid growth of Youzhu Home Decoration Co., Ltd. benefits from the unique business model and product innovation. In order to clearly present the business model, this paper uses the business model canvas tool to elaborate. Proposed by Osterwalder and Pigneur, the business model canvas includes nine modules including important partners, value proposition, key business, core resources, customer segmentation, customer relationships, Channel access, revenue sources, and cost structure ${ }^{[4]}$. The content of each module of the business model canvas is: When the internal resources of the enterprise cannot meet the needs, it is necessary to rely on important partners. Value proposition refers to a certain value that a company tries to transmit to users. Key business with core competitiveness can ensure the normal operation of its business model. Core resources are fundamental to maintaining the uniqueness and competitive advantage of the business model. According to the Resource Based View ${ }^{[5]}$, it is conducive to forming the core competitiveness of the enterprise. Customer segmentation is to sort out customers that can provide value for the company. Customer Relationship Clarifies the relationship established between the company and its customer base. Channel channels serve customers through certain channels. Revenue sources and cost structure refer to the total cost of the company's method of obtaining profit and the normal operation of the business model, respectively. Table 1 shows the business model canvas.

a2952637760@qq.com, bhabliu@zju.edu.cn 


\subsection{Value proposition}

Value proposition is the concrete expression of enterprise strategy in value realization, which originates from the analysis of industry environment and the forward-looking analysis of environment by entrepreneurs. As a home decoration company in the period of Internet of Things, there are 7 market pain points in the industry when the company was established, which are not only the stereotyped impression left by the traditional home decoration to the market, but also the various doubts of users about the Internet home decoration company. First, "fishing", that is, the set meal may turn into overlord meal. Second, it is false. The decoration materials are shoddy and cannot be prevented. The real materials do not know where to put them. Third, toss, for example, a brick used in the decoration may not be suitable, it will have to run back and forth to the market, consuming time and effort. And real-time monitoring is required in the decoration process, otherwise the decoration defects will continue. Fourth, blind, opaque material prices. Fifth, fraud, the recommended materials may not be very environmentally friendly, but the price must have doubled. Sixth, aftersales service is not guaranteed and decoration workers are poorly managed. The last point is the delay, the fixed decoration time can't be completed.

Value proposition should not only respond to the market pain points, but also be concerned about the needs of users. Compared with the past, this stage of Internet decoration meets new demands. New demand from consumption upgrades. The post- 80 and post-90 generations have gradually become the main consumer, and the young consumer groups need more high-quality, environmentally friendly and personalized living space. Decoration should be time-saving and labor-saving. At present, the post- 80 s and post- 90 consumers are under great pressure and do not have much time and energy to make many choices. The price of the products is transparent, and the chain of traditional home decoration products is too long. From manufacturers to provincial distributors to prefecture-level distributors, profits are made at every level, with extremely low price transparency. To improve the utilization rate of space, real estate prices have soared for many years, and consumers want to make full use of every inch of space, and improve delivery efficiency, eliminate private additions during decoration, and reduce supervision time on site. Personalized needs are diversified, with higher requirements for design and beauty elements, extreme experience requirements and simpler methods. Based on the market's pain points and user needs, Youzhu Home Decoration Co., Ltd. is determined by the value proposition: committed to improving the quality of decoration products and perfect customer satisfaction solutions, through standardized operation and maintenance concepts, to create a home-centric emotional IoT company, so that consumers truly experience healthy and smart home decoration products. User emotion, standardization, and health intelligence are the keywords, leading the company to provide users with temperature decoration.

\subsection{Important partners}

Partners of Qingdao Youzhu Home Decoration Co., Ltd. are distributed in various chains of the Internet home decoration ecology, which opens up all links from raw material suppliers to users, forming a closed-loop home decoration ecology from the entrance circle, industrial circle, export circle, and tool sea.

- entrance circle. The partners of the entrance circle include Haier Home, Love Office and Yugong Network. These partners are living in a symbiotic environment with Youzhu Home Decoration Co., Ltd.. Among them, Love Office is based on Uhome system and is mainly engaged in office decoration business, while Yugong Network is a one-stop supply chain service provider for intelligent apartments, focusing on providing decoration, electrical appliances, intelligence, finance, operation and other services for accommodation formats such as hotels, apartments and hostels. The four home decoration companies focus on different businesses, so the users they come into contact with can stick together in the ecology and become users' entrances to each other.

- Industrial circle. The industrial circle's partners include the integrated kitchens of Youwu and Boloni, which provide kitchen storage systems; Haosi wisdom and Rex lighting, which provide intelligent integrated systems; Naiu and Puji, which provide bathroom integrated systems; Mohan, which provide building technology solutions and building materials; and Wadi home, which provides home decoration. The business of partners in industrial circle is highly complementary and is an integral part of the decoration of smart families. The partners and Youzhu constitute the stakeholders of the smart family industry.

- Export circle. The cooperation partners in export circle and those who live in home decoration focus on win-win symbiosis in the decoration business. Cooperation resources include universities, scientific research institutions, local enterprises, design resources and other partners in the industry. The areas of cooperation include intellectual property operations such as decoration design, decoration new material development, decoration standards, patents, and certification. With the help of partners in the export circle, Youzhu have to rebuild their value chain by decorating their homes.

- Tool sea. Different types of partners with different value chains have different modes of cooperation with Youzhu Home Decoration Co., Ltd.. In order to support the construction of a horizontal value chain around demand intervention and smart families from the entrance circle and the industrial circle, as well as the construction of a vertical value chain around the integration of decoration business from the export circle, it is necessary to stick to users through the 
tool sea, and at the same time to strengthen the common sense of interests with partners. At present, there are tools including design service, incubation platform, capital, SMS and operation. The main partners include Youzhu holding, Xinzhongli, Guoxing Hua Kai, Zhicheng, etc.

\subsection{Key business}

- Modular space. The space is clearly divided and defined, and the plan is landed through the logical definition of the wall, top and bottom of the space and further modularize components to achieve prefabricated processing and production in the factory.

- Flowing process. Using high-tech and multi-layer interaction model, users' needs are combined with big data, and materials with high audience are selected to ensure product quality and strong commonality of materials.

TABLE I. THE BUSINESS MODEL CANVAS OF QINGDAO YOUZHU HOME DECOARATION COMPANY

\begin{tabular}{|c|c|c|c|c|}
\hline Important partners & Isiness & on & $\begin{array}{l}\text { customer } \\
\text { relationships }\end{array}$ & $\begin{array}{c}\text { Customer } \\
\text { segmentation }\end{array}$ \\
\hline \multirow{3}{*}{$\begin{array}{l}\text { entrance circle: } \\
\text { Haier Home, } \\
\text { Love Office } \\
\text { and Yugong } \\
\text { Network; } \\
\text { industrial } \\
\text { circle: Youwu, } \\
\text { Boloni etc; } \\
\text { export circle: } \\
\text { universities, } \\
\text { scientific } \\
\text { research } \\
\text { institutions, } \\
\text { local } \\
\text { enterprises, } \\
\text { design } \\
\text { resources and } \\
\text { other partners } \\
\text { in the industry; } \\
\text { tool sea: } \\
\text { Youzhu } \\
\text { holding, } \\
\text { Xinzhongli, } \\
\text { Guoxing Hua } \\
\text { Kai, Zhicheng, } \\
\text { etc. }\end{array}$} & $\begin{array}{ll} & \text { Modular space; } \\
\text { - } & \text { Flowing } \\
\text { process; } \\
\text { Decoration } \\
\text { productization; } \\
\text { Data analysis }\end{array}$ & \multirow{3}{*}{$\begin{array}{l}\text { committing to improving the } \\
\text { quality of decoration products } \\
\text { and perfect customer } \\
\text { satisfaction solutions, through } \\
\text { standardized operation and } \\
\text { maintenance concepts, to } \\
\text { create a home-centric } \\
\text { emotional IoT company, so } \\
\text { that consumers truly } \\
\text { experience healthy and smart } \\
\text { home decoration products. }\end{array}$} & $\begin{array}{l}\text { one-stop decoration } \\
\text { services, including } \\
\text { hard installation and } \\
\text { soft installation; } \\
\text { financial support }\end{array}$ & \multirow{3}{*}{$\begin{array}{l}\text { Individual } \\
\text { hardcover } \\
\text { products for } \\
\text { young people- } \\
\text { "baibianjia"; } \\
\text { full-chain } \\
\text { decoration } \\
\text { products- } \\
\text { "custom } \\
\text { homes"; } \\
\text { "module } \\
\text { decoration" } \\
\text { complete } \\
\text { products } \\
\text { (hard, soft, } \\
\text { and home } \\
\text { appliances) } \\
\text { for the new } \\
\text { middle class } \\
\text { - - "N- } \\
\text { home"; } \\
\text { Zero-class, a } \\
\text { luxury } \\
\text { product that } \\
\text { cooperates } \\
\text { with Kenya } \\
\text { Hara. }\end{array}$} \\
\hline & Core resources & & channel channels & \\
\hline & $\begin{array}{ll}\text { - } & \begin{array}{l}\text { High quality } \\
\text { design; }\end{array} \\
\text { - } & \text { Process } \\
\text { assurance; } \\
\text { - Standardization } \\
\text { services }\end{array}$ & & $\begin{array}{l}\text { online } \\
\text { channels: } \\
\text { information } \\
\text { platforms, e- } \\
\text { commerce } \\
\text { platforms, and } \\
\text { financial } \\
\text { platforms; } \\
\text { offline } \\
\text { channels: } 45 \\
\text { stores }\end{array}$ & \\
\hline \multicolumn{3}{|c|}{ cost structure } & \multicolumn{2}{|c|}{ revenue sources } \\
\hline \multicolumn{3}{|c|}{$\begin{array}{l}\text { IT system construction and operation costs, materials, design, } \\
\text { construction costs, supply chain construction inputs, and physical store } \\
\text { operating costs. }\end{array}$} & \multicolumn{2}{|c|}{$\begin{array}{l}\text { materials, design and construction fees, and } \\
\text { fees for merchants to settle in. }\end{array}$} \\
\hline
\end{tabular}

- Decoration productization. The production nodes of concealed projects and finish projects are scientifically scheduled to realize flow process, thus improving the working efficiency of workers by more than $30 \%$.

- Data analysis. One-price quotation for decoration allows users to stay away from the annoyance of long lists and adopt a full-package pricing method from blank to hardcover.

\subsection{Core resource}

- High quality design. It includes: in space integration design, standardized design and upgrade options, from single upgrade to unique style upgrade package, design of Moving Line for Scientific Kitchen, use the whole house weak current speed network, and the optional tone meets different aesthetic requirements.

- Process assurance. Adopt the strictest and most standardized standards in protection specifications, computer technology, waterway engineering, waterproofing engineering, oil technology, tiler display, light steel keel gypsum board ceiling, flooring, etc.

- Standardization services. First, pre-sale standardization services, second, start-up standardization services, third, construction 
standardization services; fourth, completion standardization services.

\subsection{Customer relationships}

The company provides one-stop decoration services, including hard installation and soft installation, with highquality design, process guarantee, standardized service and supply chain support for users of different demand levels. At the same time, it provides users with financial support for decoration and solves the problem of shortterm shortage of funds.

\subsection{Customer segmentation}

According to different levels of customers to provide different standards of decoration products, the company currently has four standardized products. They are: Individual hardcover products for young people"baibianjia"; full-chain decoration products-"custom homes"; "module decoration" complete products (hard, soft, and home appliances) for the new middle class "N-home"; Zero-class, a luxury product that cooperates with Kenya Hara.

\subsection{Channel access}

There are two channels for Youzhu Home decoration including online and offline channels. There is an integrated user service platform for information platforms, e-commerce platforms, and financial platforms, as well as interfaces for cooperation with e-commerce platforms. It has opened 45 stores covering 43 cities offline. By 2018, there are more than 300,000 users, more than 12 million followers in the community, and more than 35,000 households served.

\subsection{Revenue sources}

The main sources of income for Qingdao Youzhu Home Decoration include materials, design and construction fees, and fees for merchants to settle in.

\subsection{Cost structure}

The cost structure of Youzhu Home Decoration Co., Ltd. includes IT system construction and operation costs, materials, design, construction costs, supply chain construction inputs, and physical store operating costs.

\section{CONCLUSION}

Based on the case of Youzhu Home Decoration Co., Ltd., this article attempts to analyze the business model innovation. The conclusions show: business model canvas includes nine modules including important partners, value proposition, key business, core resources, customer segmentation, customer relationships, channel access, revenue sources, and cost structure, and each module plays an important role.

\section{ACKNOWLEDGMENT}

Supported by the National Natural Science Foundation of China (715721), Tianyou Youth Talent Lift Program of Lanzhou Jiaotong University

\section{REFERENCES}

1. Li Jie, Dai Xiangdong.Research on the Current Chinese National Costume Mode [J] .Furniture \& Interior Decoration, 2010 (05): 84-85.

2. Zhang Yu. Causes and Countermeasures of Development Dilemma of Home Decoration Industry [J]. Economic Forum, 2010(01):128-130.

3. Xu Jianping, Zhou Yi.Review on Business Model and Innovation Research [J] .Enterprise Reform and Management, 2020 (01): 23-24.

4. Osterwalder A, Pigneur Y. Business model generation: inovação em modelos de negócios[M]. Alta Books Editora, 2013.

5. Wernerfelt B. A resource - based view of the firm[J]. Strategic management journal, 1984, 5(2): 171-180. 